\title{
Vinasse fertirrigation alters soil resistome dynamics: an analysis based on metagenomic profiles
}

\author{
Lucas P. P. Braga ${ }^{1 *}$, Rafael F. Alves ${ }^{2}$, Marina T. F. Dellias ${ }^{1}$, Acacio A. Navarrete ${ }^{1}$, Thiago O. Basso ${ }^{3}$ and Siu M. Tsai ${ }^{1}$
}

* Correspondence:
Ippbraga@cena.usp.br
${ }^{1}$ Cell and Molecular Biology
Laboratory, Center for Nuclear
Energy in Agriculture (CENA),
University of São Paulo (USP), Av.
Centenário 303, Piracicaba
$13400-970$, São Paulo, Brazil
Full list of author information is
available at the end of the article

available at the end of the article

\begin{abstract}
Every year around $300 \mathrm{Gl}$ of vinasse, a by-product of ethanol distillation in sugarcane mills, are flushed into more than 9 Mha of sugarcane cropland in Brazil. This practice links fermentation waste management to fertilization for plant biomass production, and it is known as fertirrigation. Here we evaluate public datasets of soil metagenomes mining for changes in antibiotic resistance genes (ARGs) of soils from sugarcane mesocosms repeatedly amended with vinasse. The metagenomes were annotated using the ResFam database. We found that the abundance of open read frames (ORFs) annotated as ARGs changed significantly across 43 different families ( $p$-value $<0.05$ ). Co-occurrence network analysis revealed distinct patterns of interactions among ARGs, suggesting that nutrient amendment to soil microbial communities can impact on the coevolutionary dynamics of indigenous ARGs within soil resistome.
\end{abstract}

Keywords: Sugarcane, Vinasse, Resistome, Antibiotics, Resistance genes, Metagenomic profiles

Vinasse is a by-product of the sugar-ethanol industry produced in large quantities [1], and it is chemically composed of water, organic matter, and mineral elements [2]. It derives from the distillation process of the fermented broth, and it is obtained after the fermentation step in fuel ethanol production from sugarcane [3]. Since the 1960's, application of vinasse in natura has been used as fertilizer in the sugarcane fields of Brazil to resolve the ecological problem of its disposal within the environment, a process known as "fertirrigation" [2].

However, recent research has demonstrated that the utilization of organic compounds as fertilizers in agriculture soils can alter the selective pressure that drives antibiotic resistance genes (ARGs) on soil-borne microbial communities [4]. Soil ecosystems are considered to harbor a remarkable diversity of ARGs [4]. According to Wright et al. [5], the collection of all the ARGs and their precursors in both pathogenic and non-pathogenic bacteria can be defined by the term 'resistome'. The number of studies reporting the dynamics of resistome in the environment is growing [4]. To date, the impacting activities often reported are associated to manure fertilization and wastewater utilization in agricultural practices [6,7]. The discovery of new sources of anthropogenic practices that may affect ARGs in the environment is a challenging and timely topic, since the mechanisms regulating the spread of resistance and evolution of pathogens in environmental resistome are widely unknown [8].

(c) The Author(s). 2017 Open Access This article is distributed under the terms of the Creative Commons Attribution 4.0 International License (http://creativecommons.org/licenses/by/4.0/), which permits unrestricted use, distribution, and reproduction in any medium, provided you give appropriate credit to the original author(s) and the source, provide a link to the Creative Commons license, and indicate if changes were made. The Creative Commons Public Domain Dedication waiver (http://creativecommons.org/ publicdomain/zero/1.0/) applies to the data made available in this article, unless otherwise stated. 
Within this context, we hypothesized that vinasse fertirrigation can impact the soil resistome dynamics. Therefore, the main objective of the present study was to evaluate the impact of vinasse amendment on the abundance of ARGs from soil resistome by analyzing metagenomic datasets from a previous study [9]. In the referred study, a greenhouse experiment was performed in which vinasse was repeatedly applied to sugarcane-cultivated soils in plastic pots $(100 \mathrm{~L})$ filled with $90 \mathrm{~kg}$ of soil $(n=3)$. Vinasse applications were supplemented with urea $(450 \mathrm{~g} \mathrm{~N} \mathrm{kg-1})$ at a rate of $60 \mathrm{~kg} \mathrm{~N} \mathrm{ha-1} \mathrm{as}$ normally performed in sugarcane field production [9]. Therefore we compared the pots which received vinasse $(\mathrm{V}+)$ against pots which received only urea $(\mathrm{V}-)$. Before starting the experiment, all the pots were treated with mineral fertilizers (150 kg ha- 1 of $\mathrm{P}_{2} \mathrm{O}_{5}$ and $80 \mathrm{~kg}$ ha- 1 of $\mathrm{KCl}$ ) following the basic recommendations for sugarcane field production. Bulk soil samples were collected at the $7^{\text {th }}$ day after vinasse application $\left(7^{\text {th }}\right.$, $157^{\text {th }}$ and $217^{\text {th }}$ days after planting, dap). Vinasse samples used in the experiment were obtained downstream from fermentation process in a sugar-ethanol mill (São Paulo Brazil). Vinasse was applied to the soil at a rate of $0.06 \mathrm{~L} \mathrm{~kg}^{-1}\left(120 \mathrm{~m}^{3} \mathrm{ha}^{-1}\right)$ as a source of potassium (K) according to technical recommendations [10]. Therefore, to address the objective proposed in the present study, we used eighteen metagenomic datasets, considering the $\mathrm{V}+$ and $\mathrm{V}$ - treatments sampled in three different periods $\left(7^{\text {th }}, 157^{\text {th }}\right.$ and $217^{\text {th }}$ dap) $(n=3)$. The datasets were obtained using a MiSeq Personal Sequencing System (Illumina, San Diego, CA, USA) and are available through the Metagenomics Rapid Annotation (MG-RAST) server (http://metagenomics.anl.gov/linkin.cgi?project=10854). More details on how the metagenomic datasets were generated can be found in Navarrete et al. [9]. A total of 7,984,790 open reading frames (ORFs) assigned with PRODIGAL [11] were screened for ARGs using hmmscan from HMMER3 [12] and the hidden markov models (HMM) profiles available at the ResFam, a curated database of protein families confirmed for antibiotic resistance function [13]. The screening was performed using the default parameters for both tools and the count tables of ARGs obtained from the metagenomic datasets were analyzed using the software STAMP (Statistical Analysis of Metagenomic Profiles) [14]. The variance of significant biological importance was detected by using the Welch's test $(p$-value $<0.05)$ and Welch's inverted for calculating the confidence intervals of the effect sizes, which indicates the difference in proportions of sequences assigned to a given ARG. Error bar plots were generated to show the $p$-values and the effect sizes of ARGs found to be changed significantly (Fig. 1).

Next, in order to detect patterns of interaction among ARGs, we performed a network analysis. The models were built using the Co-occurrence Network inference tools (CoNet) [15] to detect strong and significant relationships among the different ARGs that were identified. Spearman $(-0.8>\rho>0.8)$ and Pearson $(-0.8>\mathrm{r}>0.8)$ correlations with Steinhaus similarity index $(>0.8)$ were the measures used to detect strong interactions. Relationships that were not detected by the three methods were not included in the network models. The $p$-values were computed by bootstrap (1000 interactions) based on a set of edge-specify score distribution [15], merged using the Brown method [16] and adjusted with the Benjamini-Hochberg procedure. Only relationships with $p$ values $<0.05$ were kept in the models. The models were constructed separately for the compositions of ARGs found in $\mathrm{V}+$ and $\mathrm{V}$ - across the three sampling points (7 dap, 157 dap and 217 dap), resulting in a total of 6 models. To evaluate the differences in the model structure we compared them by the change in the composition of nodes 


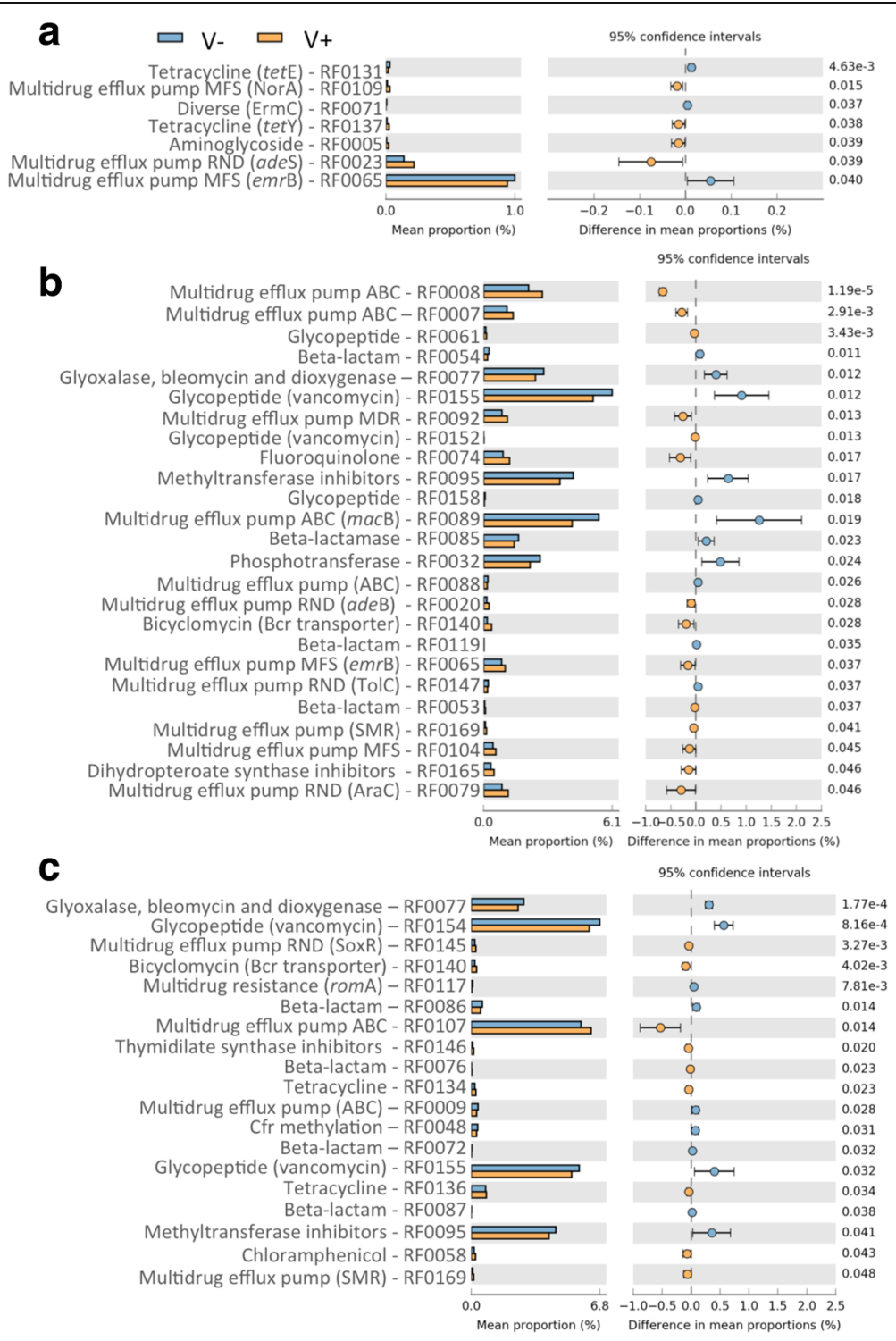

Fig. 1 Soil resistome dynamics revealed by the response of antibiotic resistance genes (ARGs) to vinasse amendment. The error bar plots indicate the ARGs that changed abundance significantly (Welch's test, $p$-value $<0.05$ ) after vinasse amendment (a) 7 days after planting (dap), (b) 157 dap and (c) 217 dap. The ARGs are represented by the antimicrobial compound that they may antagonize and its respective ID from the RESFAM database. Orange bars represent the response in vinasse-amended treatment $(\mathrm{V}+)$ and blue bars represent the response in treatment without vinasse amendment (V-)

according to betweenness centrality (BC) (a parameter interpreted as the amount of influence that a node exert over the model [17]) and by the type of interactions whether negative or positive.

Our analysis reveals that vinasse amendment caused changes in the abundance of diverse ARGs. Although no antibiotic-specific pattern of resistance could be identified as a response to vinasse amendment, several genes associated to distinct families of multidrug efflux pumps were found to be enriched in V+ samples from 7, 157 and 217 dap (Fig. 1). Besides that, worth noting that genes associated with resistance against thymidylate synthase inhibitors (RF0146), dihydropteroate synthase inhibitors (RF0165) and bicyclomycin (RF0140) 
were found to be enriched in V+ at the $157^{\text {th }}$ dap or the $217^{\text {th }}$ dap. The later (RF0140) was found to be enriched at $157^{\text {th }}$ and $217^{\text {th }}$ dap (Fig. 1b-c). Further, vinasse amendment was found to change the patterns of co-occurrence within the community of ARGs as revealed by the results predicted in the network models (Fig. 2; Additional file 1: Table S1, Additional file 2: Table S2, Additional file 3: Table S3, Additional file 4: Table S4, Additional file 5: Table: S5 and Additional file 6: Table S6). The composition of nodes, ranked by the amount of control that they exert over the network (i.e., BC), was different in all the models (Additional file 7: Table S7).

ARGs play important role in microbial ecology and evolution and are strongly associated with fitness, being responsible for detoxification by the exposure to antimicrobial compounds [4]. The results presented here indicate that vinasse applications to the soil gradually changed mechanisms of resistance (Fig. 1). Although diverse antibiotic-specific resistance genes were changed by vinasse amendments, the enrichment of multidrug efflux systems of different types such as resistance nodulation-nodulation-division (RND), major facilitator superfamily (MFS), small multidrug resistance (SMR) superfamily and ATP-binding cassette (ABC) transporters, suggests a possible large-scale effect of detoxification.

Some antimicrobial compounds, such as sulfonamides, can act targeting the enzyme dihydropteroate synthase which is involved in the folate cycle, an important pathway in cell metabolism [18]. Resistance mechanism against dihydropteroate synthase inhibitors (RF0165) was enriched in V+ (Fig. 1b). Likewise, dihydropteroate synthase, thymidilate synthase also participates on folate cycle and some drugs like 5-fluorouracil can target this enzyme. Mechanism of resistance against thymidylate synthase inhibitors (RF0146) was found to be enriched in V+ (Fig. 1c). The bicyclomycin resistance (RF0140), also enriched in $\mathrm{V}+$ (Fig. 1b-c), is part of a family of multidrug antiporters, and was demonstrated to be involved in the protection of folate cycle [19]. Folate synthesis is essential to most of microbial cells and the interference on this pathway can be harmful leading to the inability of DNA replication [20]. Therefore, vinasse application to the soil might have disturbed the microbial capacity to synthetize essential metabolic compounds, and this would explain why mechanisms of protection to enzymes were found to be enriched in $\mathrm{V}+$. This, together with the enrichment in several different types of multidrug efflux pumps, suggest a toxic effect of vinasse to soil microbes.

So far, the toxicity of vinasse to soil microbial community has not been evaluated. Vinasse applications follow agronomical recommendations taking into account plant nutritional requirements, soil characteristics and the mineral composition in vinasse. However, our results indicate that the effect of toxicity should be tested in further research. In addition, network analysis (Fig. 2; Additional file 7: Table S7) reveals that vinasse amendment can impact on ARGs coevolutionary processes [21], suggesting that vinasse amendment is capable to modify the selective pressure upon soil resistome. Nutrient amendment to soils favors copiotrophic microbes [22] and the use of antibiotics to antagonize the growth of competitors and to dominate niches may be employed as a strategy [4]. Therefore, our dataset suggests that vinasse amendment to soils contributes to interference competition within soil microbial communities. Altogether, the results presented here indicate that the spread of resistance against antimicrobial compounds within soil microbial communities by vinasse amendment is a question of concern.

In order to prevent the negative impacts related to bacterial contamination, ethanol mills utilize different compounds with antimicrobial activity such as sulphuric acid, hop 


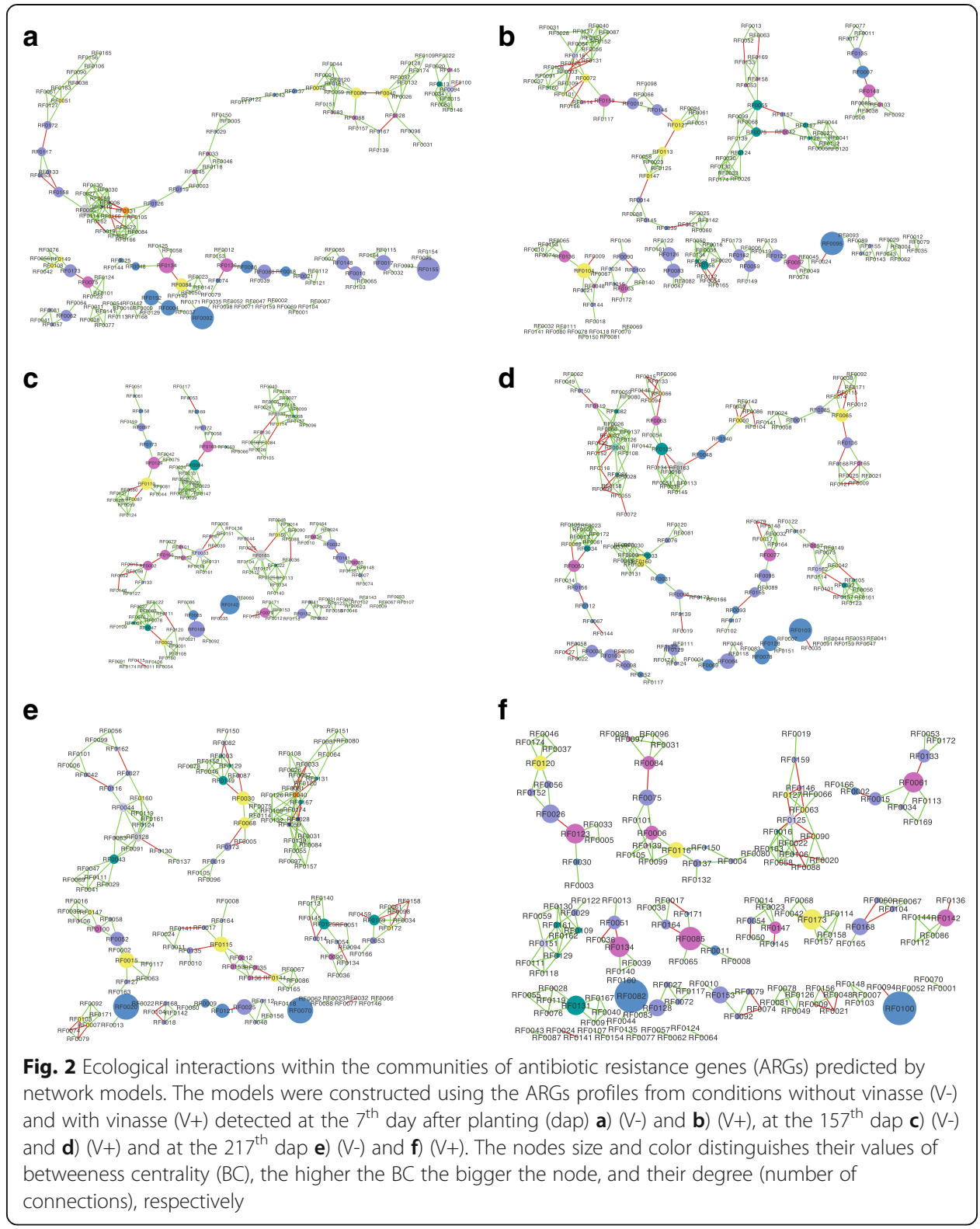

crops, chemical biocides and antibiotics [23]. Therefore, it is important to determine if such compounds remain active in vinasse and do not influence resistance genes in soils. Nevertheless, determining antibiotic concentrations in soils can be difficult [24] especially considering the low concentrations used in the industry (in the ppm range). Brazil is one of the major fuel ethanol producers worldwide (more than 23 billions L.year ${ }^{-1}$ ), yielding 10 to $15 \mathrm{~L}$ of vinasse for each $\mathrm{L}$ of ethanol produced. This, in turn, results in more than $300 \mathrm{GL}$ of vinasse being applied in 9.7 Mha $[1,2]$. It is a considerable amount of vinasse potentially being flushed into soil microbiome in sugarcane croplands. Overall, with our results we were able to provide considerable information to support the hypothesis that vinasse fertirrigation can impact the soil resistome dynamics. We outline the need for experiments to evaluate the dimension of this impact concerning the emergence of resistance in the environment and its potential implications to human health. 


\section{Additional files}

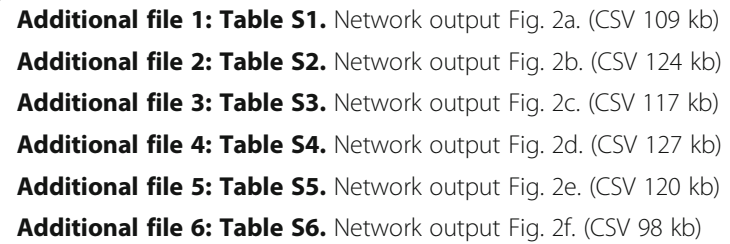

\section{Acknowledgements}

Not applicable

\section{Funding}

LPPB was supported by a doctoral grant provided by the Sao Paulo Research Foundation (FAPESP) (FAPESP 13/228452). AAN was supported by FAPESP grant (FAPESP 12/13321-7).

\section{Availability of data and materials}

The datasets supporting the conclusions of this article are available in the MG-RAST server repository, in http://metagenomics.anl.gov/linkin.cgi?project=10854. Files V9T7, V10T7, V11T7, V9T157, V10T157, V11T157, V9T217, V10T157 and V11T217 were obtained from the pots without vinasse. Files V22T7, V23T7, V24T7, V22T157, V23T157, V24T157,

V22T217, V23T217, V24T217 were obtained from the pots amended with vinasse.

\section{Authors' contributions}

LPPB, RFA and TOB conceived the idea of the manuscript. MTFD made contributions to the design of this study and discussions of the results. AAN and SMT designed the greenhouse experiment. AAN and LPPB performed the experiment. AAN obtained the soil metagenomes. LPPB analyzed the datasets and wrote the manuscript. TOB, RFA and AAN made contributions to manuscript writing. All co-authors critically revised the manuscript and approved the final version.

\section{Competing interests}

The authors declare that there are no competing interests.

\section{Consent for publication}

Not applicable

\section{Ethics approval and consent to participate}

Not applicable

\section{Publisher's Note}

Springer Nature remains neutral with regard to jurisdictional claims in published maps and institutional affiliations.

\section{Author details}

${ }^{1}$ Cell and Molecular Biology Laboratory, Center for Nuclear Energy in Agriculture (CENA), University of São Paulo (USP), Av. Centenário 303, Piracicaba 13400-970, São Paulo, Brazil. 'Brazilian Bioethanol Science and Technology Laboratory (CTBE), University of Campinas (Unicamp), Campinas, Brazil. ${ }^{3}$ Department of Chemical Engineering, Polytechnic School, University of São Paulo, São Paulo, Brazil.

Received: 8 August 2016 Accepted: 9 May 2017

Published online: 23 May 2017

\section{References}

1. Della-Bianca BE, Basso TO, Stambuk BU, Basso LC, Gombert AK. What do we know about the yeast strains from the Brazilian fuel ethanol industry? Appl Microbiol Biotechnol. 2013; doi:10.1007/s00253-012-4631-x.

2. Christofoletti CA, Escher JP, Correia JE, Marinho JF, Fontanetti CS. Sugarcane vinasse: environmental implications of its use. Waste Manag. 2013; doi:10.1016/..wasman.2013.09.005.

3. Espana-Gamboa E, Mijangos-Cortes J, Barahona-Perez L, Dominguez-Maldonado J, Hernández-Zarate G, AlzateGaviria L. Vinasses: characterization and treatments. Waste Manag Res. 2011; doi:10.1177/0734242X10387313.

4. Nesme J, Simonet P. The soil resistome: a critical review on antibiotic resistance origins, ecology and dissemination potential in telluric bacteria. Environ Microbiol. 2015; doi:10.1111/1462-2920.12631.

5. Wright GD. The antibiotic resistome: the nexus of chemical and genetic diversity. Nat Rev Microbiol. 2007; doi:10. 1038/nrmicro1614.

6. Heuer $\mathrm{H}$, Smalla K. Manure and sulfadiazine synergistically increased bacterial antibiotic resistance in soil over at least two months. Environ Microbiol. 2007; doi:10.1128/AEM.02577-10.

7. Zhu Y-G, Johnson TA, Su J-Q, Qiao M, Guo GX, Stedtfeld RD, Hashsham SA, Tiedje JM. Diverse and abundant antibiotic resistance genes in Chinese swine farms. Proc Natl Acad Sci U S A. 2013; doi:10.1073/pnas.1222743110. 
8. Finley RL, Collignon P, Larsson DGJ, McEwen SA, Li X-Z, Gaze WH, Reid-Smith R, Timinouni M, Graham Dw, Topp E. The scourge of antibiotic resistance: the important role of the environment. Clin Infect Dis. 2013;doi:10.1093/ cid/cit355.

9. Navarrete AA, Diniz TR, Braga LPP, Silva GG, Franchini JC, Rossetto R, Edwards RA, Tsai SM. Multi-analytical approach reveals potential microbial indicators in soil for sugarcane model systems. PLoS One. 2015; doi:10.1371/ journal.pone.0129765.

10. CETESB - Companhia de Tecnologia de Saneamento Ambiental. Vinhaça - Critérios e procedimentos para aplicação no solo agrícola, Norm P4.231. Sao Paulo: CETESB, 2006 6p. http://www.cetesb.sp.gov.br/wp-content/ uploads/sites/11/2013/11/P4.231_Vinhaça_-Critérios-e-procedimentos-para-aplicação-no-solo-agr\%C3\%ADcola-3aEd-2a-VERSÃO.pdf. Accessed 29 Jul 2016.

11. Hyatt $\mathrm{D}$, LoCascio PF, Hauser LJ, Uberbacher EC. Gene and translation initiation site prediction in metagenomic sequences. Bioinformatics. 2012;doi:10.1093/bioinformatics/bts429.

12. Eddy SR. Profile hidden Markov models. Bioinformatics. 1998; doi:10.1093/bioinformatics/14.9.755.

13. Gibson MK, Forsberg KJ, Dantas G. Improved annotation of antibiotic resistance functions reveals microbial resistomes cluster by ecology. ISME J. 2015; doi:10.1038/ismej.2014.106.

14. Parks DH, Tyson GW, Hugenhotz P, Beiko RG. STAMP: statistical analysis of taxonomic and functional profiles. Bioinformatics. 2014; doi:10.1093/bioinformatics/btu494.

15. Faust K, Stathirapongsasuti JF, Izard J, Segata N, Gevers D, Raes J, Huttenhower C. Microbial co-occurrence relationships in the human microbiome. Plos Comput. Biol. 2012; doi: 10.1371/journal.pcbi.1002606

16. Brown MB. 400: a method for combining non-independent one-sided tests of significance. Biometrics. 1975. doi: $10.2307 / 2529826$

17. Yoon j, Blumer A, Lee K. An algorithm for modularity analysis of directed and weighted biological networks based on edge-betweenness centrality. Bioinformatics. 2006; doi:10.1093/bioinformatics/btl533.

18. Leduc D, Escartin F,Nijhout HF, Reed MC, Liebl U, Skouloubris S, Myllykallio H. Flavin-dependent thymidylate synthase ThyX activity: implications for the folate cycle in bacteria. J. Bacteriol. 2007; doi: 10.1128/JB.01380-07.

19. Vedantam G, Guay GG, Austria NE, Doktor SZ, Nichols BP. Characterization of mutations contributing to sulfathiazole resistance in Escherichia coli. Antimicrob Agents Chemother. 1998;42:88-93.

20. Neu HC, Gootz TD. Antimicrobial chemotherapy. In: Baron S, editor. Medical microbiology. Galveston (TX): University of Texas Medical Branch at Galveston; 1996. Chapter 11.

21. Guimarães PR, Rico-Gray V, Oliveira PS, Izzo TJ, dos Reis SF, Thompson JN. Interaction intimacy affects structure and coevolutionary dynamics in mutualistic networks. Curr. Biol. 2007; doi: 10.1016/j.cub.2007.09.059.

22. Fierer N, Brandford MA, Jackson RB. Towards and ecological classification of soil bacteria. Ecology 2008;doi: 10 1890/05-1839

23. Amorim HV, Basso LC, Lopes ML. Sugar cane juice and molasses, beet molasses and sweet sorghum: composition and usage. In: Ingledew WM, Kelsall DR, Austin GD, Kluhspies C, editors. The alcohol textbook: a reference for the beverage, fuel, and industrial alcohol industries, vol. 1. Nottingham: Nottingham University Press; 2011. p. 39-46.

24. Sarmah AK, Meyer MT, Boxall ABA. A global perspective on the use, scales, exposure pathways, occurrence, fate and effect of veterinary antibiotics (VAs) in the environment. Chemosphere 2006; doi:10.1016/j.chemosphere.2006.03.026.

\section{Submit your next manuscript to BioMed Central and we will help you at every step:}

- We accept pre-submission inquiries

- Our selector tool helps you to find the most relevant journal

- We provide round the clock customer support

- Convenient online submission

- Thorough peer review

- Inclusion in PubMed and all major indexing services

- Maximum visibility for your research

Submit your manuscript at www.biomedcentral.com/submit

() BioMed Central 